\title{
Impedimetric multifunctional Sensor Based on Rubber-CNTs- orange Dye Nanocomposite Fabricated by Rubbing-in Technology
}

\author{
Muhammad Tariq Saeed Chani ${ }^{1,2, *}$, Khasan S. Karimov ${ }^{3,4}$, Hadi M. Marwani ${ }^{1,2}$, Hafiz Muhammad \\ Zeeshan $^{3}$, Mohammed M. Rahman ${ }^{1,2}$, Abdullah M. Asiri ${ }^{1,2}$ \\ ${ }^{1}$ Center of Excellence for Advanced Materials Research, King Abdulaziz University, Jeddah 21589, \\ P.O. Box 80203, Saudi Arabia \\ ${ }^{2}$ Chemistry Department, Faculty of Science, King Abdulaziz University, Jeddah 21589, P.O. Box \\ 80203, Saudi Arabia \\ ${ }^{3}$ Ghulam Ishaq Khan Institute of Engineering Sciences and Technology, Topi-23640, KPK, Pakistan \\ ${ }^{4}$ Center for Innovative Development of Science and Technologies of Academy of Sciences, Rudaki \\ Ave., 33, Dushanbe, 734025, Tajikistan \\ *E-mail: tariqchani1@gmail.com, tariq_chani@yahoo.com
}

doi: $10.20964 / 2021.07 .17$

Received: 3 March 2021 / Accepted: 15 April 2021 / Published: 31 May 2021

\begin{abstract}
This study presents the fabrication and investigation of rubber-carbon nanotubes-orange dye (rubberCNTs-OD) nanocomposite based resistive and impedimetric sensors. These shockproof multifunctional sensors may be used for displacement, pressure, force, humidity and temperature sensing. Rubbing-in technology was used to fabricate the coplanar sensors on rubber substrates of dimensions $12 \times 5 \times 5 \mathrm{~mm}^{3}$. In the middle of the substrates, the OD-CNTs mixture $(1: 1 \mathrm{wt} . \%)$ was rubbed-in to make $3 \mathrm{~mm}$ wide and 12-18 $\mu \mathrm{m}$ deep active layer. On both sides of the active layer the rubber-CNTs layers were formed, that act as conductive electrodes. The length, width and the thickness of the electrodes were 4-5 mm, $5 \mathrm{~mm}$ and 12-18 $\mu \mathrm{m}$, respectively. The resistance and the impedance of the sensors decreased under the effect of compressive displacement, pressure, humidity and temperature. These reductions were $-43 \Omega / \mu \mathrm{m}$ to $-73 \Omega / \mu \mathrm{m},-3950 \Omega-\mathrm{cm}^{2} / \mathrm{kgf}$ to $-6008 \Omega-\mathrm{cm}^{2} / \mathrm{kgf},-187 \Omega / \% \mathrm{RH}$ to $-981 \Omega / \% \mathrm{RH}$ and $-216 \Omega /{ }^{\circ} \mathrm{C}$ to $270 \Omega /{ }^{\circ} \mathrm{C}$, respectively. The force (in perpendicular direction to the length) causes to increase the resistance and impedance $(60 \Omega / \mathrm{gf}$ to $300 \Omega / \mathrm{gf})$. The probable reasons of the observed changes in the resistance and impedance of the sensor have been described.
\end{abstract}

Keywords: Semiconductor; Shockproof; Displacement sensor; Force sensor; Pressure sensor; Humidity sensor; Temperature sensor.

\section{$\underline{\text { FULL TEXT }}$}


(C) 2021 The Authors. Published by ESG (www.electrochemsci.org). This article is an open access article distributed under the terms and conditions of the Creative Commons Attribution license (http://creativecommons.org/licenses/by/4.0/). 